\title{
Effects of amino acids and energy intake during late gestation of high-performing gilts and sows on litter and reproductive performance under commercial conditions ${ }^{1,2}$
}

\author{
M. A. D. Gonçalves, * K. M. Gourley, † S. S. Dritz,* \\ M. D. Tokach, $\uparrow$ N. M. Bello, $\$$ J. M. DeRouchey,$\uparrow$ J. C. Woodworth, $\uparrow$ and R. D. Goodband $\dagger^{3}$ \\ *Department of Diagnostic Medicine/Pathobiology, College of Veterinary \\ Medicine, $\uparrow$ Department of Animal Sciences and Industry, College of Agriculture, \\ and $¥$ Department of Statistics, College of Arts and Sciences, Kansas State University, Manhattan 66506-0201
}

\begin{abstract}
The objective of this study was to determine the effects of AA and energy intake during late gestation on piglet birth weight and reproductive performance of high-performing (14.5 total born) gilts and sows housed under commercial conditions. At $\mathrm{d}$ 90 of gestation, a total of 1,102 females (PIC 1050) were housed in pens by parity group (gilts or sows) with approximately 63 gilts and 80 sows in each pen, blocked by BW within each pen, and each female was randomly assigned to dietary treatments within $\mathrm{BW}$ block. Dietary treatments consisted of combinations of 2 standardized ileal digestible (SID) AA intakes (10.7 or $20.0 \mathrm{~g} / \mathrm{d}$ SID Lys and other AA met or exceeded the NRC [2012] recommendations) and 2 energy intakes ( 4.50 or $6.75 \mathrm{Mcal} / \mathrm{d}$ intake of NE) in a $2 \times 2$ factorial arrangement. Data were analyzed using generalized linear mixed models specified to recognize pen as the experimental unit for parity and the individual female as the experimental unit for dietary treatments. Results indicate an overall positive effect of high energy intake on BW gain during late gestation, although this effect was more manifest under conditions of high, as opposed to low, AA intake (interaction, $P<0.001$ ). Furthermore, the magnitude of BW gain response to
\end{abstract}

increased energy intake was greater $(P<0.001)$ for sows compared with gilts. Sows fed high energy intake had a reduced probability of piglets born alive $(P<$ $0.004)$ compared with those fed low energy, but no evidence for differences was found in gilts. This can be explained by an increased probability $(P=0.002)$ of stillborns in sows fed high energy intake vs. sows fed low energy intake. There were no evidences for differences among dietary treatments in litter birth weight and individual piglet birth weight of total piglets born. However, individual born alive birth weight was approximately $30 \pm 8.2 \mathrm{~g}$ heavier $(P=0.011)$ for females fed high, as opposed to low, energy intake. Furthermore, piglets born alive were approximately $97 \pm 9.5 \mathrm{~g}$ heavier $(P<0.001)$ for sows than for gilts. Preweaning mortality was decreased $(P=0.034)$ for females fed high AA intake compared with females fed low AA intake regardless of energy level. In conclusion, 1) BW gain of gilts and sows depended not only on energy but also on AA intake, 2) sows fed increased amount of energy had an increased stillborn rate, and 3) increased energy intake during late gestation had a positive effect on individual piglet birth weight with no evidence for such an effect for AA intake.

Key words: amino acids, birth weight, energy, gestation, gilts, sows

J. Anim. Sci. 2016.94:1993-2003 doi:10.2527/jas2015-0087

\section{INTRODUCTION}

\footnotetext{
${ }^{1}$ Contribution number 16-136-J from the Kansas Agric. Exp. Stn., Manhattan, KS 66506-0210.

${ }^{2}$ Appreciation is expressed to Hord Livestock Company (Bucyrus, Ohio) for providing the animals and research facilities and to Ryan Hughes, Jason Dunfee, and Matt Davis for technical assistance.

${ }^{3}$ Corresponding author: Goodband@ksu.edu

Received November 10, 2015.

Accepted March 20, 2016.
}

Increased litter size over the last decades reduced the uterine space available for fetal growth and development, thus reducing individual piglet birth weight (Town et al., 2005). Lower birth weight has been associated with reduced piglet survivability, wean weight, and market weight (Bergstrom, 2011; Douglas et al., 
2013). However, few nutritional options have been identified to help mitigate the reduction in birth weight associated with large litter sizes (Goodband et al., 2013).

Evidence from recent studies does not support any impact of increased feed intake in early or mid gestation on piglet birth weight (Heyer et al., 2004; Lawlor et al., 2007). However, increasing feed intake in late gestation has been shown to improve piglet birth weight (Cromwell et al., 1989; Shelton et al., 2009; Soto et al., 2011). Cromwell et al. (1989) observed a 40-g increase in piglet birth weight when gilts and sows were fed an extra $1.4 \mathrm{~kg}$ of feed daily during late gestation. Shelton et al. (2009) and Soto et al. (2011) observed an increase in piglet birth weight in litters from gilts fed increased amount of feed during late gestation, although this was not apparent in sow litters. Yet the effects of increased feed allowance during late gestation on piglet birth weight remains unclear for commercial conditions, particularly in high-performing herds ( $>14.5$ total piglets born/sow). Furthermore, because all studies reported increased feed intake, which increased both energy and $\mathrm{AA}$, it is unclear if the influences on piglet birth weight are due to dietary AA or energy content.

The objective of this study was to determine the effects of AA and energy intake during late gestation on piglet birth weight and reproductive performance of high-performing gilts and sows housed under commercial conditions. The hypothesis was that both maternal dietary AA and energy in the late gestation period would positively affect piglet birth weight in an additive manner.

\section{MATERIALS AND METHODS}

\section{General}

The Kansas State University Institutional Animal Care and Use Committee approved the protocol used in this experiment. The experiment was conducted at a commercial sow farm in northern Ohio during the summer season. Females were individually housed and fed once a day from d 0 to 40 of gestation and then were group housed (1.86 and $1.67 \mathrm{~m}^{2} /$ animal for gilts and sows, respectively) in static groups from d 40 to 111 of gestation. A total of 16 pens were used in the study. Each group pen was equipped with an electronic sow feeding station (Schauer, Prambachkirchen, Austria) and 2 cup waterers. All females had ad libitum access to water.

\section{Animals and Diets}

From d 0 to 89 of gestation, females were fed a common corn-soybean meal diet with $0.59 \%$ standardized ileal digestible (SID) Lys according to body condition (thin, ideal, and fat females were fed 3.2, 2.0, and
$1.8 \mathrm{~kg} / \mathrm{d}$, respectively), following standard practice at this commercial farm. Feed disappearance before the experiment (d 40 to 90; data not shown) was monitored and there was no statistical difference among the dietary treatments, validating the randomization process. To be eligible for enrollment in this experiment at d 90 of gestation, females must not have 1) recorded a return to estrus event during the previous production cycle, 2) had an abortion during the previous cycle, 3) lameness of moderate or greater severity, or 4) BCS less than 2 on a 1-to-5 scale. At d 90 of gestation, a total of 1,102 females (PIC 1050; PIC, Hendersonville, TN; 741 gilts and 361 sows) were housed in pens by parity group (gilts or sows) with approximately 63 gilts or 80 sows in each pen, blocked by BW within each pen, and each female was randomly assigned to dietary treatments within BW block in a pen. The parity for sows after farrowing was 4.0 (SD 1.9). Dietary treatments consisted of combinations of 2 SID AA intakes (10.7 or $20.0 \mathrm{~g} / \mathrm{d}$ SID Lys, and other SID AA met or exceeded the NRC [2012] recommendations as a ratio to Lys) and 2 energy intakes ( 4.50 or $6.75 \mathrm{Mcal} / \mathrm{d}$ intake of NE) in a $2 \times 2$ factorial arrangement. All other nutrients met or exceeded the NRC (2012) recommendations during the whole gestation period. The NRC (2012) estimates the Lys requirement from $d 90$ of gestation until farrowing at $18.5 \mathrm{~g}$ SID Lys/d for gilts and $13.0 \mathrm{~g}$ SID Lys/d for sows with 14.5 total born with an individual piglet birth weight of $1.40 \mathrm{~kg}$. The NE requirement estimate is $6.37 \mathrm{Mcal} \mathrm{NE} / \mathrm{d}$ for gilts and $6.24 \mathrm{Mcal} \mathrm{NE} / \mathrm{d}$ for sows (NRC 2012). The low AA (10.7 g/d SID Lys) and low energy (4.50 Mcal NE/d) intake dietary treatment in this experiment was structured to be representative of practices used in commercial farms that do not increase the amount of feed in late gestation. The NE intake on the low-energy treatment was calculated to meet the maintenance requirement for a $230-\mathrm{kg} \mathrm{BW}$ female. Thus, the low energy intake was expected to provide near or just above maintenance for the majority of the females in the study. The high-energy treatment was defined as 6.75 Mcal NE/d because it is above the requirement of gilts and sows estimated by NRC (2012) and also to represent the levels of intake used in those farms that increase the amount of feed in late gestation. The NRC (2012) SID Lys requirement estimate for gilts at $\mathrm{d} 111$ of gestation is $19.6 \mathrm{~g} / \mathrm{d}$. The high-AA treatment was formulated to provide $20 \mathrm{~g} / \mathrm{d}$ SID Lys to be above the NRC (2012) estimated requirement for gilts and sows during the last third of gestation and to be in accordance with findings from Srichana (2006).

Two diets were formulated (Table 1) and delivered at 4 different ratios and feed allowance levels to achieve the desired dietary treatments for the $2 \times 2$ factorial treatment structure (Table 2). Diets were balanced on a Ca-to-standardized total tract digestible $\mathrm{P}$ ratio basis. 
Table 1. Diet composition (as-fed basis) ${ }^{1}$

\begin{tabular}{|c|c|c|}
\hline \multirow[b]{2}{*}{ Ingredient } & \multicolumn{2}{|c|}{ SID $^{2}$ Lys, $\%$} \\
\hline & 0.40 & 1.06 \\
\hline Corn & 87.97 & 62.47 \\
\hline Soybean meal $(46 \% \mathrm{CP})$ & 8.06 & 33.59 \\
\hline Monocalcium phosphate & 1.60 & 1.25 \\
\hline Limestone & 1.50 & 1.45 \\
\hline Salt & 0.50 & 0.50 \\
\hline L-Lys $\mathrm{HCl}$ & 0.045 & 0.045 \\
\hline DL-Met & - & 0.200 \\
\hline L-Thr & 0.035 & 0.210 \\
\hline Choline chloride $60 \%$ & 0.100 & 0.100 \\
\hline Vitamin/mineral premix ${ }^{3}$ & 0.150 & 0.150 \\
\hline Phytase $^{4}$ & 0.035 & 0.035 \\
\hline \multicolumn{3}{|l|}{ Calculated analysis } \\
\hline \multicolumn{3}{|l|}{ SID AA, $\%$} \\
\hline Lys & 0.40 & 1.06 \\
\hline Ile:Lys & 80 & 72 \\
\hline Leu:Lys & 219 & 144 \\
\hline Met:Lys & 41 & 47 \\
\hline Met and Cys:Lys & 79 & 71 \\
\hline Thr:Lys & 81 & 80 \\
\hline Trp:Lys & 21 & 22 \\
\hline Val:Lys & 94 & 76 \\
\hline $\mathrm{NE}, \mathrm{kcal} / \mathrm{kg}$ & 2,521 & 2,386 \\
\hline $\mathrm{CP}, \%$ & 11.20 & 21.50 \\
\hline $\mathrm{Ca}, \%$ & 0.85 & 0.86 \\
\hline $\mathrm{P}, \%$ & 0.62 & 0.66 \\
\hline Available P, \% & 0.52 & 0.48 \\
\hline $\mathrm{STTD}^{5} \mathrm{P}, \%$ & 0.52 & 0.52 \\
\hline Ca:Total P & 1.37 & 1.29 \\
\hline Ca:STTD P & 1.64 & 1.64 \\
\hline
\end{tabular}

${ }^{1}$ Diets were fed from d 90 to 111 of gestation. Corn and soybean meal were analyzed for total AA content before diet formulation and NRC (2012) SID digestibility values were used in the diet formulation.

${ }^{2} \mathrm{SID}=$ standardized ileal digestible.

${ }^{3}$ Provided, per kilogram of diet, $40 \mathrm{mg}$ Mn from manganese oxide, $99 \mathrm{mg}$ Fe from iron sulfate, $132 \mathrm{mg} \mathrm{Zn}$ from zinc sulfate, $16.5 \mathrm{mg} \mathrm{Cu}$ from copper sulfate, $0.33 \mathrm{mg}$ I from ethylenediamine dihydriodide, $0.30 \mathrm{mg}$ Se from sodium selenite, $0.23 \mathrm{mg}$ biotin, $1.65 \mathrm{mg}$ folic acid, $3.31 \mathrm{mg}$ pyridoxine, 9,921 IU vitamin A, 2,202 IU vitamin $D_{3}$, 66 IU vitamin $E, 4.3 \mathrm{mg}$ vitamin $K, 33$ $\mathrm{mg}$ pantothenic acid, $43 \mathrm{mg}$ niacin, $10 \mathrm{mg}$ riboflavin, and $33 \mu \mathrm{g}$ vitamin $\mathrm{B}_{12}$.

${ }^{4}$ Quantum Blue $2 \mathrm{G}$ (AB Vista Feed Ingredients, Marlborough, UK) provided 701 phytase units per kilogram of diet with a release of $0.12 \%$ STTD P.

${ }^{5} \mathrm{STTD}=$ standardized total tract digestible.

Phytase was included in both diets at the same level, with release considered to be $0.12 \%$ for standardized total tract digestible P. No AA or energy release was considered for phytase. Daily feed allowance was measured with an electronic sow feeding system and feed delivered was assumed to be consumed. Note that the feed bowls were monitored daily to ensure that the settings of the electronic sow feeding system were adequate to avoid spillage or wastage. Additionally, feeding station calibration was monitored twice a week by weighing 10 samples from each dispenser in each station.
Table 2. Experimental dietary treatment structure ${ }^{1}$

\begin{tabular}{|c|c|c|c|c|}
\hline \multirow[b]{6}{*}{ Item } & \multicolumn{4}{|c|}{ AA intake } \\
\hline & \multicolumn{2}{|c|}{ Low } & \multicolumn{2}{|c|}{ High } \\
\hline & \multicolumn{4}{|c|}{ Energy intake } \\
\hline & Low & High & Low & High \\
\hline & \multicolumn{4}{|c|}{ Delivered ratio, ${ }^{2} \%$} \\
\hline & $71: 29$ & 100:0 & $0: 100$ & $50.5: 49.5$ \\
\hline Feed allowance, $\mathrm{kg} / \mathrm{d}$ & 1.81 & 2.68 & 1.89 & 2.75 \\
\hline Energy, Mcal NE/d & 4.50 & 6.75 & 4.50 & 6.75 \\
\hline SID $^{3}$ Lys, g/d & 10.7 & 10.7 & 20.0 & 20.0 \\
\hline \multicolumn{5}{|c|}{$\begin{array}{l}{ }^{1} \text { Dietary treatment structure based on the } 2 \text { diets presented in Table } 1 . \\
2 \text { Delivered ratio between } 0.40 \text { and } 1.06 \% \text { SID Lys diets to achieve the } \\
\text { desired dietary treatments on an intake basis. Other AA met or exceeded } \\
\text { the NRC (2012) recommendations as a ratio to Lys. }\end{array}$} \\
\hline
\end{tabular}

At d 111 of gestation, females were moved to the farrowing house and fed $3.6 \mathrm{~kg} / \mathrm{d}$ of a common lactation diet with $1.25 \%$ SID Lys provided until farrowing and then were provided the same diet ad libitum thereafter. Day of transfer to the farrowing house and gestation length were evaluated and there was no evidence of differences between dietary treatments (data not shown). Both gestation and lactation diets were corn-soybean meal based and presented in meal form.

The response variables measured were female ADFI from d 90 to 111 of gestation, individual female BW at d 90 and 111 of gestation, total number of piglets born, number of piglets born alive, number of stillborns, number of mummified fetuses, number of dead piglets, and number of removed piglets; individual piglet BW at birth was collected at $0530 \mathrm{~h}$ for the litters farrowed between $1200 \mathrm{~h}$ (noon) from the previous day and $0530 \mathrm{~h}$ and at $1200 \mathrm{~h}$ for the litters farrowed between 0530 and $1200 \mathrm{~h}$. Litter birth weight and individual piglet birth weight were then calculated with and without the inclusion of stillborns and mummified fetuses. The CV of birth weight within litter was calculated by dividing the individual piglet birth weight SD by the average piglet birth weight of that specific litter for both total piglets born and piglets born alive.

Following farrowing and data collection, litter size was equalized after weighing individual piglets in a blinded manner regardless of dietary treatment; no pigs were added to litters thereafter. Dead and removed pigs were recorded. Removed pigs were considered pigs removed from the female due to loss of body condition and were put on an off-test nursing female. Lactation length, wean-to-estrus interval (WEI), and percentage of females bred until $7 \mathrm{~d}$ after weaning were also recorded.

On the subsequent cycle, no dietary treatments were applied and females were fed a common diet with $0.59 \%$ SID Lys accordingly to body condition (thin, ideal, and fat females were fed $3.2,2.0$, and $1.8 \mathrm{~kg} / \mathrm{d}$, respectively) 
until d 90 of gestation and then feed allowance was increased by $0.9 \mathrm{~kg} / \mathrm{d}$ for thin and ideal condition females. To evaluate subsequent female performance, farrowing rate, total number of piglets born, number of born alive, number of stillborns, and number of mummified fetuses from the next reproductive cycle were also recorded.

\section{Diet Sampling and Analysis}

Representative samples of corn and soybean meal were collected each week for $5 \mathrm{wk}$ and analyzed in duplicate for total AA (except Trp; method 994.12; AOAC, 2012), Trp (method 13904:2005; AOAC, 2005), and CP (method 990.03; AOAC, 2012) by Ajinomoto Heartland Inc. (Chicago, IL), and values were used in diet formulation. Samples of the diets were submitted to Ward Laboratories, Inc. (Kearney, $\mathrm{NE}$ ) for analysis of DM (method 935.29; AOAC, 2012), Crude fiber (method 978.10; AOAC, 2012; for preparation and Ankom 2000 Fiber Analyzer, Ankom Technology, Fairport, NY), ash (method 942.05; AOAC, 2012), crude fat (method 920.39 a; AOAC, 2012; for preparation and ANKOM XT20 Fat Analyzer, Ankom Technology), Ca, and P (method $968.08 \mathrm{~b}$; AOAC, 2012; for preparation and using an ICAP 6500, ThermoElectron Corp., Waltham, MA). Diet samples were taken from each electronic feeding station twice a week and then CP and total AA analyses were conducted in duplicate on 3 composite samples per treatment by Ajinomoto Heartland Inc.

\section{Statistical Analysis}

Data were analyzed using generalized linear mixed models (GLMM) whereby the linear predictor included parity group, dietary treatments, and all interactions as fixed effects as well as the random effects of pen nested within parity and BW block crossed with pen nested within parity. So specified, models recognized pen as the experimental unit for parity and the individual female as the experimental unit for dietary treatments, after accounting for BW blocking.

Female ADFI from d 90 to 111 of gestation, individual female BW at d 90 of gestation, female BW gain from d 90 to 111 of gestation, individual piglet BW at birth, total litter birth weight, lactation length, and WEI were fitted assuming a normal distribution of the response variable. In these cases, residual assumptions were checked using standard diagnostics on Studentized residuals and were found to be reasonably met.

In turn, total number of piglets born and litter size after equalization were fitted assuming a negative binomial distribution on the response, whereas born alive, stillborn, mummified, dead, removed, and weaned pig-
Table 3. Chemical analysis of the diets (as-fed basis) ${ }^{1}$

\begin{tabular}{|c|c|c|c|c|}
\hline \multirow[b]{4}{*}{ Item } & \multicolumn{4}{|c|}{ AA intake } \\
\hline & \multicolumn{2}{|c|}{ Low } & \multicolumn{2}{|c|}{ High } \\
\hline & \multicolumn{4}{|c|}{ Energy intake } \\
\hline & Low & High & Low & High \\
\hline \multicolumn{5}{|c|}{ Proximate analysis, $\%$} \\
\hline $\mathrm{DM}$ & $89.3(87.4)^{2}$ & $89.3(87.2)$ & $90.1(88.0)$ & $89.8(87.6)$ \\
\hline $\mathrm{CP}$ & $13.6(14.2)$ & $10.4(11.2)$ & $20.9(21.5)$ & $15.9(16.3)$ \\
\hline Crude fiber & $1.6(2.2)$ & $1.6(2.1)$ & $2.1(2.5)$ & $1.9(2.3)$ \\
\hline $\mathrm{Ca}$ & $0.84(0.85)$ & $0.74(0.85)$ & $0.79(0.85)$ & $0.78(0.85)$ \\
\hline $\mathrm{P}$ & $0.59(0.63)$ & $0.59(0.62)$ & $0.64(0.66)$ & $0.64(0.64)$ \\
\hline Fat & $2.6(3.0)$ & $2.5(3.2)$ & $2.8(2.7)$ & $2.5(2.9)$ \\
\hline Ash & $4.5(5.1)$ & $4.0(4.9)$ & $5.1(5.8)$ & $4.5(5.3)$ \\
\hline \multicolumn{5}{|l|}{ Total AA, \% } \\
\hline Lys & $0.66(0.69)$ & $0.48(0.48)$ & $1.14(1.21)$ & $0.81(0.84)$ \\
\hline Ile & $0.50(0.52)$ & $0.38(0.38)$ & $0.84(0.87)$ & $0.61(0.62)$ \\
\hline Leu & $1.16(1.22)$ & $0.96(1.00)$ & $1.67(1.74)$ & $1.32(1.37)$ \\
\hline Met & $0.26(0.29)$ & $0.18(0.19)$ & $0.45(0.54)$ & $0.31(0.36)$ \\
\hline Met and Cys & $0.48(0.52)$ & $0.36(0.38)$ & $0.76(0.85)$ & $0.56(0.61)$ \\
\hline Thr & $0.54(0.56)$ & $0.40(0.39)$ & $0.92(0.98)$ & $0.65(0.68)$ \\
\hline $\operatorname{Trp}$ & $0.13(0.14)$ & $0.12(0.10)$ & $0.24(0.26)$ & $0.17(0.18)$ \\
\hline Val & $0.59(0.59)$ & $0.47(0.45)$ & $0.90(0.94)$ & $0.69(0.69)$ \\
\hline His & $0.34(0.39)$ & $0.26(0.31)$ & $0.52(0.58)$ & $0.38(0.45)$ \\
\hline Phe & $0.63(0.69)$ & $0.49(0.54)$ & $1.00(1.05)$ & $0.75(0.79)$ \\
\hline
\end{tabular}

${ }^{1}$ Diet samples were taken from each electronic feeding station twice a week, and then $\mathrm{CP}$ and total $\mathrm{AA}$ analyses were conducted in duplicate on composite samples by Ajinomoto Heartland Inc. (Chicago, IL).

${ }^{2}$ Values in parentheses indicate those calculated from diet formulation and are based on values from the NRC (2012) with the exception of total AA content from corn and soybean meal, which were analyzed before diet formulation by Ajinomoto Heartland Inc.

lets as well as females bred until $7 \mathrm{~d}$ after weaning and subsequent farrowing were fitted using a binomial distribution. Furthermore, the CV of birth weight within the litter considering total piglets born and piglets born alive were approximated with a $\beta$ distribution, as all observed values lay between 0 and 1 . Overdispersion was assessed using a maximum-likelihood-based Pearson $\chi^{2} /$ degrees of freedom statistic and accounted for as needed (Stroup, 2012). The final models used for inference were fitted using REML estimation. Degrees of freedom were estimated using the Kenward-Rogers approach (Kenward and Roger, 1997).

Estimated means and corresponding SEM are reported for all interactive means and also for treatment combinations of interest consistent with significance of interaction or main effects, following the hierarchical principle of inference (Milliken and Johnson, 2009). Pairwise comparisons were conducted on such means using a Bonferroni adjustment to prevent inflation of Type I error due to multiple comparisons. Statistical models were fitted using the GLIMMIX procedure of SAS (version 9.3; SAS Inst. Inc., Cary, NC). Results were considered significant at $P \leq 0.05$ and marginally significant at $0.05<P \leq 0.10$. 
Table 4. Least squares mean estimates (SEM) of the effects of AA and energy intake during late gestation of highperforming gilts and sows on piglet birth weight and reproductive performance under commercial conditions ${ }^{1}$

\begin{tabular}{|c|c|c|c|c|c|c|c|c|}
\hline \multirow[b]{5}{*}{ Item } & \multicolumn{4}{|c|}{ Gilts } & \multicolumn{4}{|c|}{ Sows } \\
\hline & \multicolumn{8}{|c|}{ AA intake 2} \\
\hline & Low & High & Low & High & Low & High & Low & High \\
\hline & \multicolumn{8}{|c|}{ Energy intake ${ }^{2}$} \\
\hline & Low & Low & High & High & Low & Low & High & High \\
\hline BW d 90, kg & $175.5(1.51)$ & $174.7(1.51)$ & $175.3(1.52)$ & $175.3(1.51)$ & $227.3(2.21)$ & $227.4(2.19)$ & $225.8(2.20)$ & $228.7(2.22)$ \\
\hline $\mathrm{BW}$ gain $\mathrm{d} 90$ to $111, \mathrm{~kg}$ & $13.4(0.44)$ & $16.4(0.44)$ & $18.4(0.44)$ & $24.5(0.44)$ & $10.5(0.67)$ & $13.4(0.67)$ & $18.5(0.68)$ & $23.0(0.67)$ \\
\hline ADFI d 90 to $111, \mathrm{~kg}$ & $1.8(0.01)$ & $1.8(0.01)$ & $2.6(0.01)$ & $2.6(0.01)$ & $1.8(0.01)$ & $1.9(0.01)$ & $2.7(0.01)$ & $2.7(0.01)$ \\
\hline Total piglets born, no. & $14.2(0.22)$ & $14.1(0.21)$ & $14.1(0.22)$ & $14.2(0.21)$ & $15.3(0.34)$ & $14.8(0.33)$ & $15.1(0.32)$ & $15.5(0.35)$ \\
\hline Born alive, \% & $94.6(0.5)$ & $95.0(0.5)$ & $93.6(0.5)$ & $94.2(0.5)$ & $93.3(0.8)$ & $93.1(0.8)$ & $89.6(1.0)$ & $90.8(1.0)$ \\
\hline Mummified fetuses, $\%$ & $1.8(0.28)$ & $1.7(0.27)$ & $2.6(0.36)$ & $2.5(0.34)$ & $1.6(0.36)$ & $3.0(0.54)$ & $3.4(0.57)$ & $2.8(0.54)$ \\
\hline Stillborn, \% & $3.5(0.40)$ & $3.2(0.38)$ & $3.6(0.40)$ & $3.2(0.37)$ & $5.1(0.69)$ & $3.7(0.58)$ & $6.9(0.83)$ & $6.1(0.79)$ \\
\hline \multicolumn{9}{|l|}{ Total born } \\
\hline Litter birth weight, kg & $18.0(0.24)$ & $17.9(0.24)$ & $17.8(0.23)$ & $17.9(0.23)$ & $20.7(0.34)$ & $20.2(0.34)$ & $20.6(0.34)$ & $21.0(0.35)$ \\
\hline Piglet birth weight, $\mathrm{kg}$ & $1.25(0.01)$ & $1.27(0.01)$ & $1.28(0.01)$ & $1.28(0.01)$ & $1.36(0.02)$ & $1.36(0.02)$ & $1.38(0.02)$ & $1.36(0.02)$ \\
\hline Birth weight CV, \% & $20.2(0.66)$ & $20.4(0.65)$ & $21.7(0.68)$ & $21.3(0.67)$ & $25.6(1.04)$ & $26.2(1.05)$ & $27.3(1.06)$ & $25.9(1.07)$ \\
\hline \multicolumn{9}{|l|}{ Born alive } \\
\hline Litter birth weight, $\mathrm{kg}$ & $17.2(0.23)$ & $17.2(0.23)$ & $17.1(0.23)$ & $17.3(0.23)$ & $19.6(0.34)$ & $19.5(0.34)$ & $19.1(0.34)$ & $20.0(0.35)$ \\
\hline Piglet birth weight, $\mathrm{kg}$ & $1.28(0.01)$ & $1.28(0.01)$ & $1.30(0.01)$ & $1.31(0.01)$ & $1.36(0.02)$ & $1.39(0.02)$ & $1.40(0.02)$ & $1.41(0.02)$ \\
\hline Birth weight $\mathrm{CV}, \%$ & $18.0(0.47)$ & $18.2(0.47)$ & $18.5(0.48)$ & $18.3(0.47)$ & $23.9(0.77)$ & $23.2(0.75)$ & $23.2(0.76)$ & $21.9(0.77)$ \\
\hline Litter size after equalization, no. & $14.5(0.30)$ & $14.4(0.30)$ & $14.6(0.30)$ & $14.3(0.30)$ & $14.2(0.42)$ & $13.7(0.40)$ & $13.9(0.44)$ & $14.0(0.43)$ \\
\hline Piglets weaned, $\%$ & $84.3(0.82)$ & $86.5(0.77)$ & $86.2(0.78)$ & $86.4(0.78)$ & $80.7(1.31)$ & $81.5(1.26)$ & $82.0(1.35)$ & $83.2(1.26)$ \\
\hline Preweaning mortality, $\%$ & $10.3(0.69)$ & $8.0(0.61)$ & $8.9(0.64)$ & $8.4(0.63)$ & $13.7(1.15)$ & $13.1(1.11)$ & $13.3(1.21)$ & $12.1(1.11)$ \\
\hline Piglet Removal rate, $\%$ & $5.0(0.55)$ & $5.2(0.57)$ & $4.5(0.52)$ & $4.9(0.55)$ & $5.1(0.82)$ & $5.00(0.79)$ & $4.3(0.77)$ & $4.3(0.75)$ \\
\hline Lactation length, $d$ & $24.9(0.27)$ & $24.9(0.27)$ & $24.7(0.46)$ & $24.0(0.46)$ & $24.4(0.41)$ & $24.1(0.40)$ & $24.2(0.72)$ & $24.2(0.68)$ \\
\hline Wean-to-estrus interval, d & $6.8(0.43)$ & $5.9(0.44)$ & $6.6(0.45)$ & $6.2(0.44)$ & $4.4(0.71)$ & $4.2(0.68)$ & $4.8(0.77)$ & $4.9(0.71)$ \\
\hline Females bred by $7 \mathrm{~d}$ after weaning, $\%$ & $87.8(2.88)$ & $88.9(2.81)$ & $85.1(3.26)$ & $89.1(2.77)$ & $98.3(1.72)$ & $98.3(1.68)$ & $94.0(3.37)$ & $96.2(2.68)$ \\
\hline \multicolumn{9}{|l|}{ Subsequent performance } \\
\hline Farrowing rate, $\%$ & $88.3(2.88)$ & $88.4(2.91)$ & $84.2(3.36)$ & $88.6(2.86)$ & $93.7(3.20)$ & $93.9(3.13)$ & $91.3(3.96)$ & $87.1(4.67)$ \\
\hline Total piglets born, no. & $13.2(0.35)$ & $13.2(0.35)$ & $13.0(0.36)$ & $13.4(0.35)$ & $14.7(0.56)$ & $15.5(0.56)$ & $15.5(0.62)$ & $15.0(0.59)$ \\
\hline Born alive, $\%$ & $93.9(0.64)$ & $93.4(0.68)$ & $93.9(0.67)$ & $94.3(0.61)$ & $91.1(1.12)$ & $91.6(1.07)$ & $92.2(1.1)$ & $92.0(1.11)$ \\
\hline Mummified fetuses, $\%$ & $1.8(0.33)$ & $1.8(0.34)$ & $2.4(0.40)$ & $2.0(0.35)$ & $1.7(0.46)$ & $2.9(0.60)$ & $3.1(0.67)$ & $2.3(0.57)$ \\
\hline Stillborn, \% & $4.3(0.54)$ & $4.7(0.58)$ & $3.8(0.52)$ & $3.7(0.48)$ & $7.0(1.01)$ & $5.5(0.86)$ & $4.7(0.84)$ & $5.5(0.92)$ \\
\hline
\end{tabular}

${ }^{1}$ A total of 1,102 females (PIC 1050; PIC, Hendersonville, TN ) were used with 274 to 278 females per dietary treatment combination. Probability values are presented in Table 5 .

${ }^{2}$ Refer to Tables 1 and 2 for dietary composition and treatment structure, respectively.

\section{RESULTS}

\section{General}

Chemical analysis of DM, CP, crude fiber, crude fat, $\mathrm{Ca}, \mathrm{P}$, ash, and total AA reasonably met the formulated values (Table 3). Average daily feed intake from each treatment was reasonably close to the feed allowance (Tables 2 and 4).

\section{Female BW Gain during Late Gestation}

Within each parity group, we observed no evidence for any differences among treatments in initial BW at $90 \mathrm{~d}$ of gestation, thus validating our randomization process (Table 5). Regarding BW gain during late gestation, significant interactions were apparent, specifi- cally between AA and energy $(P<0.001)$ and between parity and energy $(P<0.001)$. An overall positive effect of high energy intake was identified on the magnitude of BW gain during late gestation, although this effect was more manifest (energy $\times \mathrm{AA}, P<0.001$ ) under conditions of high AA intake compared with conditions of low AA intake $(8.8 \pm 0.36$ and $6.5 \pm 0.37 \mathrm{~kg}$, respectively; Fig. 1A). Furthermore, the magnitude of BW gain response to increased energy intake was greater for sows than for gilts $(8.8 \pm 0.42$ and $6.5 \pm$ $0.29 \mathrm{~kg}$, respectively; $P<0.001$; Fig. 1B).

\section{Litter Size}

There was no evidence for any differences in the number of total piglets born among dietary treatments. However, across diets, sows had more $(P<0.001)$ 
Table 5. Probability values corresponding to main effects of, and interactions among, AA intake, energy intake, and parity during late gestation of high-performing gilts and sows on piglet birth weight and reproductive performance under commercial conditions ${ }^{1}$

\begin{tabular}{|c|c|c|c|c|c|c|c|}
\hline Item & AA $\times$ energy $\times$ parity & AA $\times$ energy & Parity $\times$ AA & Parity $\times$ energy & Parity & AA & Energy \\
\hline BW d $90, \mathrm{~kg}$ & 0.463 & 0.230 & 0.187 & 0.856 & 0.001 & 0.438 & 0.926 \\
\hline BW gain d 90 to $111, \mathrm{~kg}$ & 0.128 & 0.001 & 0.131 & 0.001 & 0.028 & 0.001 & 0.001 \\
\hline ADFI d 90 to $111, \mathrm{~kg}$ & 0.608 & 0.834 & 0.050 & 0.707 & 0.001 & 0.001 & 0.001 \\
\hline Total piglets born, no. & 0.249 & 0.154 & 0.938 & 0.492 & 0.001 & 0.901 & 0.552 \\
\hline Born alive, $\%$ & 0.569 & 0.483 & 0.718 & 0.092 & 0.002 & 0.261 & 0.001 \\
\hline Mummified fetuses, $\%$ & 0.047 & 0.068 & 0.134 & 0.910 & 0.199 & 0.461 & 0.001 \\
\hline Stillborn, $\%$ & 0.456 & 0.628 & 0.471 & 0.014 & 0.001 & 0.049 & 0.013 \\
\hline Mummified fetuses + stillborn, $\%$ & 0.569 & 0.483 & 0.718 & 0.092 & 0.002 & 0.261 & 0.001 \\
\hline \multicolumn{8}{|l|}{ Total born } \\
\hline Litter birth weight, $\mathrm{kg}$ & 0.453 & 0.189 & 0.795 & 0.241 & 0.001 & 0.904 & 0.489 \\
\hline Piglet birth weight, $\mathrm{kg}$ & 0.885 & 0.546 & 0.446 & 0.643 & 0.001 & 0.993 & 0.365 \\
\hline Birth weight CV, \% & 0.610 & 0.266 & 0.792 & 0.533 & 0.001 & 0.678 & 0.091 \\
\hline \multicolumn{8}{|l|}{ Born alive } \\
\hline Litter birth weight, $\mathrm{kg}$ & 0.405 & 0.145 & 0.459 & 0.954 & 0.001 & 0.184 & 0.945 \\
\hline Piglet birth weight, $\mathrm{kg}$ & 0.489 & 0.602 & 0.641 & 0.743 & 0.001 & 0.292 & 0.011 \\
\hline Birth weight CV, \% & 0.955 & 0.674 & 0.466 & 0.204 & 0.001 & 0.522 & 0.564 \\
\hline Litter size after equalization, no. & 0.462 & 0.761 & 0.987 & 0.986 & 0.103 & 0.516 & 0.904 \\
\hline Piglets weaned, $\%$ & 0.365 & 0.516 & 0.789 & 0.781 & 0.001 & 0.120 & 0.087 \\
\hline Preweaning mortality, $\%$ & 0.254 & 0.494 & 0.443 & 0.882 & 0.001 & 0.034 & 0.356 \\
\hline Piglet removal rate, $\%$ & 0.963 & 0.804 & 0.653 & 0.670 & 0.724 & 0.830 & 0.155 \\
\hline Lactation length, $d$ & 0.363 & 0.578 & 0.735 & 0.338 & 0.448 & 0.341 & 0.310 \\
\hline Wean-to-estrus interval, d & 0.873 & 0.581 & 0.467 & 0.529 & 0.001 & 0.395 & 0.455 \\
\hline Females bred by $7 \mathrm{~d}$ after weaning, $\%$ & 0.913 & 0.700 & 0.990 & 0.284 & 0.001 & 0.595 & 0.192 \\
\hline \multicolumn{8}{|l|}{ Subsequent performance } \\
\hline Farrowing rate, $\%$ & 0.436 & 0.927 & 0.456 & 0.428 & 0.167 & 0.981 & 0.163 \\
\hline Total piglets born, no. & 0.208 & 0.578 & 0.859 & 0.819 & 0.001 & 0.710 & 0.830 \\
\hline Born alive, $\%$ & 0.459 & 0.808 & 0.893 & 0.875 & 0.004 & 0.904 & 0.284 \\
\hline Mummified fetuses, $\%$ & 0.250 & 0.080 & 0.501 & 0.975 & 0.220 & 0.976 & 0.212 \\
\hline Stillborn, \% & 0.172 & 0.450 & 0.682 & 0.921 & 0.012 & 0.974 & 0.040 \\
\hline
\end{tabular}

${ }^{1} \mathrm{~A}$ total of 1,102 females (PIC 1050; PIC, Hendersonville, TN) were used with 274 to 278 females per dietary treatment combination.

total piglets born than gilts. In turn, energy intake showed a marginally significant effect on the probability of born alive for sows and gilts (parity $\times$ energy, $P=0.092)$. Specifically, sows fed high energy intake had a reduced probability $(P<0.004)$ of piglets born alive, compared with those fed low energy, but no evidence for differences was found in gilts, regardless of level of AA intake in their diet. This may be partially explained by an increased probability of stillborns $(P=$ 0.002 ) in sows fed high energy intake as opposed to sows fee low energy intake (Fig. 2). Additionally, after accounting for the effect of energy intake, the probability of stillborns was reduced $(P=0.049)$ in females fed high AA intake. Furthermore, an AA $\times$ energy $\times$ parity $(P=0.047)$ interaction was identified on probability of mummified fetuses, whereby sows fed low energy and high AA intake had increased probability compared with sows fed low energy and low AA intake $(P=0.048)$; no evidence for dietary effects was apparent in gilts. As expected, there were no statisti- cal differences among litter size after equalization as a function of dietary treatment or parity.

\section{Piglet Birth Weight}

Considering the total number of piglets born, there was no evidence for differences among dietary treatments on litter birth weight or on individual piglet birth weight (Tables 4 and 5). However, litter birth weight and individual piglet birth weight were heavier in sows $(P<0.001)$ than in gilts, whereas within-litter birth weight $\mathrm{CV}$ was greater $(P<0.001)$ in sows than in gilts. Furthermore, a marginally greater $(P=0.091)$ within-litter birth weight CV was observed in females fed high energy compared with females fed low energy independent of parity level.

When litter birth weight and individual piglet birth weight for piglets born alive were considered, weights were heavier in sow litters $(P<0.001)$ compared with gilt litters. More specifically, piglets born alive from 

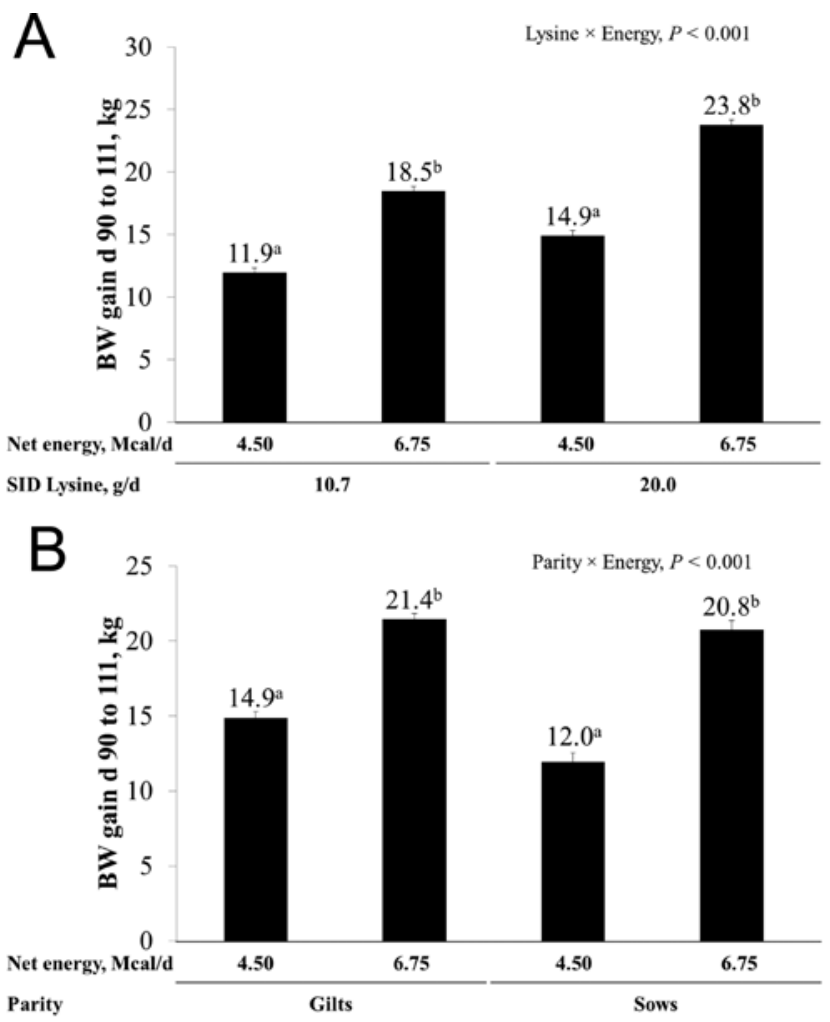

Figure 1. (A) Estimated mean $( \pm \mathrm{SEM}) \mathrm{BW}$ gain of gilts and sows fed different AA and energy intake levels from d 90 to 111 of gestation. Other AA met or exceeded the NRC (2012) recommendations as a ratio to Lys. ${ }^{\text {a,b }}$ Within a standardized ileal digestible Lys level, means with different superscript differ $(P<0.05)$. (B) Estimated mean $( \pm$ SEM) BW gain of gilts and sows fed different energy intake levels from d 90 to 111 of gestation. ${ }^{\mathrm{a}, \mathrm{b}}$ Within parity level, means with different superscript differ $(P<0.05)$.

sows were approximately $97 \pm 9.5 \mathrm{~g}$ heavier $(P<$ $0.001)$ than those from gilts. Furthermore, individual born alive birth weight (Fig. 3) was approximately $30 \pm 8.2 \mathrm{~g}$ heavier $(P=0.011)$ for females fed high energy intake compared with low energy intake females, regardless of AA intake or parity level. There was no evidence for differences in the within-litter birth weight $\mathrm{CV}$ of piglets born alive among dietary treatments, although this $\mathrm{CV}$ was greater $(P<0.001)$ in sows than gilts.

\section{Preweaning Mortality, Removal Rate, and Piglets Weaned}

Preweaning mortality was decreased $(P=0.034)$ in piglets suckling from females fed high AA intake compared with females fed low AA intake during late gestation regardless of energy level. After adjusting for dietary treatments, sows showed greater preweaning mortality than gilts $(P<0.001)$. There were no statistically significant differences among dietary treatments on removal rate; however, there was a marginal increase in the probability of piglets weaned $(P=0.087)$ when females were fed high, as opposed to low, energy.

\section{Lactation Length, Percentage Bred by $7 d$, and Wean-to-Estrus Interval}

There was no evidence for differences in lactation length among dietary treatment or parity level. For all dietary treatments, the percentage of females bred by $7 \mathrm{~d}$ after weaning was greater $(P=0.001)$ for sows than for gilts. This was explained by a lower $(P=0.001) \mathrm{WEI}$ in sows compared with gilts. However, there was no evidence for any differences among dietary treatments in percentage of females bred by $7 \mathrm{~d}$ after weaning or WEI.

\section{Subsequent Female Performance}

For the subsequent reproductive cycle, there was no evidence for any effects of dietary treatments on farrowing rate, number of total piglets born, probability of piglets born alive, and probability of mummified fetuses. However, females previously fed high energy had lower $(P=0.040)$ probability of stillborn piglets in the subsequent cycle compared with those fed low energy regardless of AA level.

On the subsequent cycle, sows had greater $(P<$ $0.001)$ number of total piglets born compared with gilts regardless of dietary treatments. In turn, gilts had increased $(P<0.004)$ probability of piglets born alive compared with sows, and this was at least partially explained by a decreased $(P<0.012)$ probability of stillborns on the subsequent cycle.

\section{DISCUSSION}

The main objective of this study was to evaluate the impact of AA and energy intake levels during late gestation on piglet birth weight and subsequent maternal reproductive performance. The treatments were structured as a factorial arrangement to determine the relative impact of AA compared with energy. Although the factorial arrangement allows for the relative comparison of treatment differences, the drawback of this design is that it is that requirements cannot be estimated because

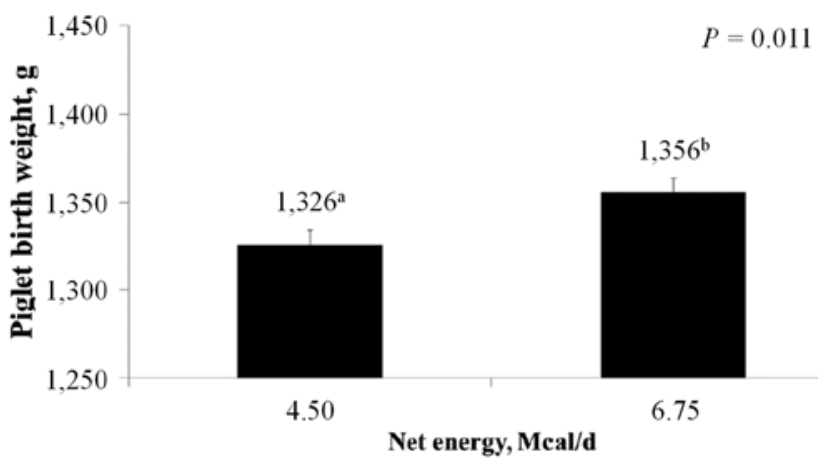

Figure 2. Estimated stillborn rate ( \pm SEM) for gilts and sows fed different energy intake levels fed from d 90 to 111 of gestation. ${ }^{\text {a,b Within }}$ parity level, means with different superscript differ $(P<0.05)$. 


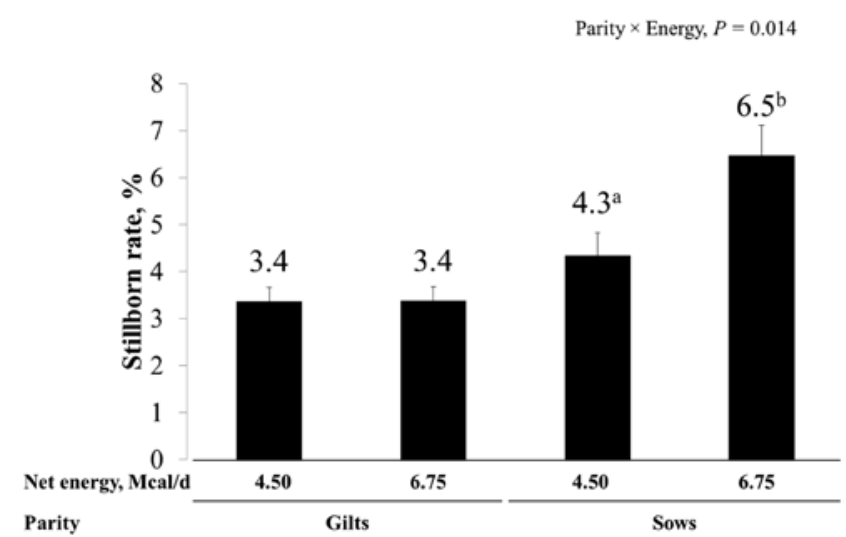

Figure 3. Estimated mean ( \pm SEM) individual born alive piglet birth weight for different energy intake levels fed from d 90 to 111 of gestation. ${ }^{\mathrm{a}, \mathrm{b}}$ Means with different superscript differ $(P<0.05)$.

for the main effects, there are only 2 treatment levels. However, the relative differences allow for an estimation to determine if an AA or energy titration would be the most productive follow up experiment. Also, it should be noted that the factorial treatment structure was based on an absolute amount of AA and energy intake per day. It was expected that gilts and sows would have different requirements. Therefore, by feeding similar amounts of AA and energy, this served as an internal validation of the response. One example is the difference in BW gain between gilts and sows fed the low energy intake. Because sows were heavier, they had a higher proportion of energy intake used for maintenance and, thus, had lower weight gain compared with gilts.

\section{Female BW Gain during Late Gestation}

The interactive effects of dietary AA and energy intake from increased feed intake on BW have been well documented in nursery pigs (Schneider et al., 2010), finishing pigs (Main et al., 2008; Nitikanchana et al., 2015), and lactating sows (Tokach et al., 1992). To the author's knowledge, this is the first report of an interaction between AA and energy intake on BW gain of reproductive females during late gestation. Our results are in agreement with the body of literature in nursery and finishing pigs in which a simultaneous increase in AA and energy intake is needed to maximize growth until the genetic ceiling for protein deposition is reached (Campbell and Taverner, 1988). This is an important finding that deserves further quantification given that the current NRC (2012) spreadsheet model predicts gestating female BW gain only based on energy intake but not based on AA intake or an AA:calorie ratio. This study provides evidence that $\mathrm{AA}$ intake should be considered when estimating BW gain of gilts and sows during late gestation.
Increasing energy intake increased BW gain during late gestation in both gilts and sows. However, sows fed low energy intake had reduced BW gain compared with gilts. This could be partly explained because gilts have a higher growth rate than sows and maintenance in late gestation represents approximately $60 \%$ of the energy requirement for gilts and $80 \%$ of the energy requirement for sows (NRC, 2012). Therefore, partitioning of energy toward growth is greater in gilts compared with sows whereas partitioning of energy toward maintenance is greater in sows compared with gilts.

\section{Piglet Birth Weight}

Different experiments in the literature report piglet birth weight in different ways. Some did not report the total litter weight (Cromwell et al., 1989), whereas some did not report individual total born weight (Soto et al., 2011). In this study, birth weights from total born and from piglets born alive are both reported on an individual basis as well as on a litter basis. This distinction is important because there was no evidence for any differences in litter birth weight or individual total born piglet birth weight among dietary treatments; however, individual born alive piglet birth weight was heavier in piglets from females fed high energy intake compared with piglets from females fed low energy intake.

Interestingly, the observed dietary energy effect in the current study had an estimated magnitude similar to another large sample size study conducted in multiple farms and multiple seasons by Cromwell et al. (1989), where the authors observed a 40-g improvement in birth weight of piglets born alive by feeding increased amount of feed from d 90 of gestation. Additionally, in our study, it is worth noting that parity had more than a 3-fold greater effect (approximately 97 vs. $30 \mathrm{~g}$ ) on individual born alive piglet birth weight than energy intake.

Srichana (2006) suggested a SID Lys requirement for gilts in late gestation of $20 \mathrm{~g} / \mathrm{d}$ estimated through nitrogen balance. Another study using an AA oxidation technique reported that the Lys requirement in late gestation is $17.4 \mathrm{~g} / \mathrm{d}$ (Samuel et al., 2012). Similarly, our findings showed that increasing SID Lys intake from 10.7 to $20 \mathrm{~g} / \mathrm{d}$ indeed increased female BW gain; however, AA did not significantly affect piglet birth weight. This finding is interesting from the perspective that the SID AA level to maximize growth of the gestating female is probably different from the level to maximize piglet birth weight because fetal growth is a priority during late gestation (Theil et al., 2014). Therefore, the gestating female will likely catabolize protein to supply AA to the growing fetuses. Genetic selection for terminal lines has focused on maximized leanness as it improves feed efficiency (Chen et al., 2003); therefore, 
because approximately $50 \%$ of the genetic merit of a terminal pig comes from the dam, most breeding stock companies would have terminal traits (i.e., ADG, G:F) in the selection index of dam lines. Consequently, gilt and sow body composition have shifted toward increased lean rather than fat (Lewis and Southern, 2000). Therefore, given that individual piglet birth weight was affected by increasing levels of energy, it could be speculated that females during late gestation are limited in energy, rather than limited in AA.

\section{Reproductive Performance}

Piglets born alive were reduced in sows fed high energy intake due to an increased probability of stillborns, but not in gilts. Fat sows have been reported to have a longer farrowing duration (Madec and Leon, 1992), which can cause a higher probability of stillborn piglets (Zaleski and Hacker, 1993); however, Borges et al. (2005) did not observe any association between sow body condition and the probability of stillborns, and Le Cozler et al. (2002) observed a reduced probability of stillborns in heavier weight sows. Therefore, the literature is unclear on the effects of sow body condition or $\mathrm{BW}$ on the probability of stillborns. These results from the literature are probably further confounded by others factors such as lean-to-fat ratio and diet composition. However, existing evidence about a relationship between higher parities and increased probability of stillborns may be related to poorer uterine muscle tone (Zaleski and Hacker, 1993; Leenhouwers et al., 1999; Borges et al., 2005). Our data is consistent with this line of thought as we observed a higher stillborn rate in sows compared with gilts. In addition, it has been reported that the stillborn rate is greater in heavier piglets (Arthur et al., 1989). In our study, piglets were heavier at birth in 1) sows compared with gilts and 2) females fed higher energy compared with females fed low energy. This might explain our result on a greater stillborn rate in sows fed high energy compared with sows fed low energy.

The stillborn rate was reduced in females fed high AA intake, which is in agreement with Magnabosco et al. (2013), who observed a marginally significant reduction of $1.1 \%$ percentage points in the probability of stillborns for gestating sows fed higher Lys. In another study, females were fed low or high AA during lactation and a marginal reduction in stillborn in the subsequent farrowing for females fed high AA was observed (Musser et al., 1998). This is an interesting finding as changes would be expected in the body composition (lean-to-fat ratio) of females fed high AA intake, which could, in turn, positively impact uterine muscle tone and reduce dystocia (Almond et al., 2006). The only AA $\times$ energy $\times$ parity interaction was that sows fed low energy and high AA intake had an increased probability of mummified fetuses compared with sows fed low energy and low AA intake, although no evidence for any dietary effects was apparent in gilts. This finding has not been previously reported in the literature and the biological reasons for it could not be explained in this experiment.

Preweaning mortality improved for litters suckling from females fed high AA intake compared with litters suckling from females fed low AA intake regardless of energy level. It should be noted that because litter size was standardized irrespective of treatment, no inference can be made on any factor intrinsic to the piglet inutero effect. Nonetheless, this result is consistent with the findings of a proof-of-concept study (DeGeeter et al., 1972), which showed that low CP during gestation negatively influenced preweaning mortality. Yet given that increased AA have not been reported to increase milk fat (Dourmad et al., 1998; Kusina et al., 1999), it remains unclear how dietary AA influence preweaning mortality. Sows fed higher AA had marginally higher milk protein content (Yang et al., 2009), which potentially could be related to the changes in survivability. Certainly, as litter sizes increase and preweaning mortality becomes more challenging on many farms, the enhancement of piglet survival based on late gestation feeding is an area that needs further exploration.

\section{Parity Effects}

Even after dietary effects were accounted for, sows had greater number of total piglets born, litter birth weight, piglet birth weight, and birth weight CV compared with gilts. These results are in agreement with the current body of literature (Pettigrew et al., 1986; Gama and Johnson, 1993; Milligan et al., 2002). As shown in past studies (Mabry et al., 1996; Guedes and Nogueira, 2001), sows had shorter WEI than gilts and, consequently, greater percentage of females bred by $7 \mathrm{~d}$ after weaning.

\section{Subsequent Female Performance}

Even though there were no statistical differences among dietary treatments in the subsequent parity performance for total piglets born and piglets born alive, females fed high energy in the previous cycle had a lower probability of stillborns in the subsequent cycle. This suggests no evidence for a long-term impact or carryover effect of dietary treatments on reproductive performance of gilts and sows, as dietary treatments were applied only in the first cycle, whereas in the subsequent cycle, females were under standard farm procedures common to all. 


\section{A Comment on Modern Statistical Modeling}

The statistical analysis in the current study entailed state-of-the-art GLMM, which evaluated each response variable according to the nature of its distribution (Stroup, 2012). By contrast to the GLM that assumes normality on the response variable, GLMM are particularly useful for nonnormal responses for which a normal approximation may not be the best approach, for example, in the presence of count (i.e., total piglets born), binomial (i.e., piglets born alive), and binary (i.e., farrowing rate) data (Stroup, 2012). In fact, GLMM allows the researcher to recognize the proper nature of a response variable and the corresponding statistical distribution to be used for its modeling. For example, an observation on a given sow farrowing a litter of size 13 with all piglets born alive can be argued to carry different information (and probably health implications) compared with an observation from another sow that may have also farrowed 13 piglets born alive but from a larger litter (20 total born for example). Recording such observations using just a count of 13 born alive in either case, as is often the case with swine farm database management systems, fails to recognize the difference in information contained by both observations and can easily lead to misleading conclusions. Instead, a more insightful understanding of the situation may be feasible if one recognized the nature of the variable born alive as binomial with number of trials given by the litter size and with probability of born alive estimated from the data. Indeed, properly recognizing the nature of the response variable has important implications for sound inference and subsequent decisions making (Stroup, 2012). In turn, inappropriate use of statistical distributions can create misleading interpretations of the data (Limpert and Stahel, 2011). In fact, it is possible that inconsistent findings among sow experiments may be explained, at least partially, by inappropriate use of statistical distributions to model nonnormal responses that are common in swine production systems.

\section{Implications}

In conclusion, 1) BW gain of swine females depends not only on energy but also on AA intake levels, and it does so differently for gilts and sows; 2) high energy intake caused an increased stillborn rate in sows; 3) preweaning mortality was reduced in piglets suckling from females with high AA intake; and 4) increased energy intake during late gestation had a positive, although modest, effect on individual piglet birth weight; no evidence for such effect was apparent for levels of AA intake. Therefore, increasing feed intake during late gestation would be recommended for gilts but not for sows due to the negative effects of increased energy intake on the stillborn rate in sows.

\section{LITERATURE CITED}

Almond, G., W. L. Flowers, L. Batista, and S. D’Allaire. 2006. Disease of the reproductive system. In: B. E. Straw, J. J. Zimmerman, S. D'Allaire, and D. J. Taylor, editors, Diseases of swine. 9th ed. Blackwell Publishing, Ames, IA. p. 113-147.

AOAC. 2005. Official methods of analysis. 15th ed. Assoc. Official. Anal. Chem. Washington. DC.

AOAC. 2012. Official methods of analysis of AOAC International. 19th ed. AOAC Int., Gaithersburg, MD.

Arthur, G. H., D. E. Noakes, and H. Pearson. 1989. Veterinary reproduction and obstetrics. 6th ed. Bailliere Tindall, London, UK. p. 193-218.

Bergstrom, J. R. 2011. Effects of birth weight, finishing feeder design, and dietary astaxanthin and ractopamine $\mathrm{HCl}$ on the growth, carcass, and pork quality characteristics of pigs; and meta-analyses to improve the prediction of pork fat quality. PhD Diss., Kansas State University, Manhattan, KS.

Borges, V. F., M. L. Bernardi, F. P. Bortolozzo, and I. Wentz. 2005. Risk factors for stillbirth and foetal mummification in four Brazilian swine herds. Prev. Vet. Med. 70:165-176. doi:10.1016/j.prevetmed.2005.03.003

Campbell, R. G., and M. R. Taverner. 1988. Genotype and sex effects on the relationship between energy intake and protein deposition in growing pigs. J. Anim. Sci. 66:676-686.

Chen, P., T. J. Baas, J. C. M. Dekkers, K. J. Koehler, and J. W. Mabry. 2003. Evaluation of strategies for selection for lean growth rate in pigs. J. Anim. Sci. 81:1150-1157.

Cromwell, G. L., D. D. Hall, A. J. Clawson, G. E. Combs, D. A. Knabe, C. V. Maxwell, P. R. Noland, D. E. Orr, and T. J. Prince. 1989. Effects of additional feed during late gestation on reproductive performance of sows: A cooperative study. J. Anim. Sci. 67:3-14.

DeGeeter, M. J., V. W. Hays, D. D. Kratzer, and G. L. Cromwell. 1972. Reproductive performance of gilts fed diets low in protein during gestation and lactation. J. Anim. Sci. 35:772-777.

Douglas, S. L., S. A. Edwards, E. Sutcliffe, P. W. Knap, and I. Kyriazakis. 2013. Identification of risk factors associated with poor lifetime growth performance in pigs. J. Anim. Sci. 91:4123-4132. doi:10.2527/jas.2012-5915

Dourmad, J. Y., J. Noblet, and M. Etienne. 1998. Effect of protein and lysine supply on performance, nitrogen balance, and body composition changes of sows during lactation. J. Anim. Sci. 76:542-550.

Gama, L. L., and R. K. Johnson. 1993. Changes in ovulation rate, uterine capacity, uterine dimensions, and parity effects with selection for litter size in swine. J. Anim. Sci. 71:608-617.

Goodband, R. D., M. D. Tokach, M. A. D. Gonçalves, J. C. Woodworth, S. S. Dritz, and J. M. DeRouchey. 2013. Nutritional enhancement during pregnancy and effects on reproduction in swine. Anim. Front. 3:68-75. doi:10.2527/af.2013-0036

Guedes, R. M., and R. H. Nogueira. 2001. The influence of parity order and body condition and serum hormones on weaning-to-estrus interval of sows. Anim. Reprod. Sci. 67:91-99. doi:10.1016/ S0378-4320(01)00108-7

Heyer, A., H. K. Andersson, J. E. Lindberg, and K. Lundström. 2004. Effect of extra maternal feed supply in early gestation on sow and piglet performance and production and meat quality of growing/finishing pigs. Acta Agric. Scand., Sect. A 54:44-55. 
Kenward, M. G., and J. H. Roger. 1997. Small sample inference for fixed effects from restricted maximum likelihood. Biometrics 53:983-997. doi:10.2307/2533558

Kusina, J., J. E. Pettigrew, A. F. Sower, M. E. White, B. A. Crooker, and M. R. Hathaway. 1999. Effect of protein intake during gestation and lactation on the lactational performance of primiparous sows. J. Anim. Sci. 77:931-941.

Lawlor, P. G., P. B. Lynch, M. K. O'Connell, L. McNamara, P. Reid, and N. C. Stickland. 2007. The influence of over feeding sows during gestation on reproductive performance and pig growth to slaughter. Arch. Tierz. 50(Special Issue):82-91.

Le Cozler, Y. L., C. Guyomarc'h, X. Pichodo, P. Y. Quinio, and H. Pellois. 2002. Factors associated with stillborn and mummified piglets in high-prolific sows. Anim. Res. 51:261-268. doi:10.1051/animres:2002017

Leenhouwers, J. I., T. van der Lende, and E. F. Knol. 1999. Analysis of stillbirth in different lines of pig. Livest. Prod. Sci. 57:243253. doi:10.1016/S0301-6226(98)00171-7

Lewis, A. J., and L. L. Southern. 2000. Swine nutrition. CRC Press, Boca Raton, FL.

Limpert, E., and W. A. Stahel. 2011. Problems with using the normal distribution - and ways to improve quality and efficiency of data analysis. PLoS One 6:e21403. doi:10.1371/journal. pone.0021403

Mabry, J. W., M. S. Culbertson, and D. Reeves. 1996. Effects of lactation length on weaning-to-first-service interval, first-service farrowing rate, and subsequent litter size. J. Swine Health Prod. 4:185-188.

Madec, F., and E. Leon. 1992. Farrowing disorders in the sow: A field study. J. Vet. Med., A 39:433-444. doi:10.1111/j.1439-0442.1992.tb00202.x

Magnabosco, D., T. Bierhals, R. R. Ribeiro, H. S. Cemin, J. E. G. Faccin, M. L. Bernardi, I. Wentz, and F. P. Bortolozzo. 2013. Lysine supplementation in late gestation of gilts: Effects on piglet birth weight, and gestational and lactational performance. Cienc. Rural 43:1464-1470. doi:10.1590/S0103-84782013000800020

Main, R. G., S. S. Dritz, M. D. Tokach, R. D. Goodband, and J. L. Nelssen. 2008. Determining an optimum lysine:calorie ratio for barrows and gilts in a commercial finishing facility. J. Anim. Sci. 86:2190-2207. doi:10.2527/jas.2007-0408

Milligan, B. N., D. Fraser, and D. L. Kramer. 2002. Within-litter birth weight variation in the domestic pig and its relation to pre-weaning survival, weight gain, and variation in weaning weights. Livest. Prod. Sci. 76:181-191. doi:10.1016/S03016226(02)00012-X

Milliken, G. A., and D. E. Johnson. 2009. Analysis of messy data: Designed experiments. Vol. 1, 2nd ed. CRC Press, Boca Raton, FL. doi:10.1201/EBK1584883340

Musser, R. E., R. D. Goodband, J. L. Nelssen, M. D. Tokach, and S. S. Dritz. 1998. Effects of increased dietary lysine on sow and litter performance. Kansas State University, Agricultural Experiment Station and Cooperative Extension Service, Manhattan, KS. p. 17-20.
Nitikanchana, S., S. S. Dritz, M. D. Tokach, J. M. DeRouchey, R. D. Goodband, and B. J. White. 2015. Regression analysis to predict growth performance from dietary net energy in growing-finishing pigs. J. Anim. Sci. 93:2826-2839. doi:10.2527/jas.2015-9005

NRC. 2012. Nutrient requirements of swine. 11th rev. ed. Natl. Acad. Press, Washington, DC.

Pettigrew, J. E., S. G. Cornelius, R. L. Moser, T. R. Heeg, H. E. Hanke, K. P. Miller, and C. D. Hagen. 1986. Effects of oral doses of corn oil and other factors on preweaning survival and growth of piglets. J. Anim. Sci. 62:601-612.

Samuel, R. S., S. Moehn, P. B. Pencharz, and R. O. Ball. 2012. Dietary lysine requirement of sows increases in late gestation. J. Anim. Sci. 90:4896-4904. doi:10.2527/jas.2011-4583

Schneider, J. D., M. D. Tokach, S. S. Dritz, J. L. Nelssen, J. M. DeRouchey, and R. D. Goodband. 2010. Determining the effect of lysine:calorie ratio on growth performance of ten- to twentykilogram of body weight nursery pigs of two different genotypes. J. Anim. Sci. 88:137-146. doi:10.2527/jas.2008-1204

Shelton, N. W., C. R. Neill, J. M. DeRouchey, M. D. Tokach, R. D. Goodband, J. L. Nelssen, and S. S. Dritz. 2009. Effects of increasing feeding level during late gestation on sow and litter performance. Kansas State University, Agricultural Experiment Station and Cooperative Extension Service, [Manhattan, KS. p. 38-50.

Soto, J., L. Greiner, J. Connor, and G. Allee. 2011. Effects increasing feeding levels in sows during late gestation on piglet birth weights. J. Anim. Sci. 89:86 (Abstr.).

Srichana, P. 2006. Amino acid nutrition in gestating and lactating sows. PhD Diss., University of Missouri, Columbia, MO.

Stroup, W. W. 2012. Generalized linear mixed models: Modern concepts, methods and applications. CRC Press, Boca Raton, FL.

Theil, P. K., C. Lauridsen, and H. Quesnel. 2014. Neonatal piglet survival: Impact of sow nutrition around parturition on fetal glycogen deposition and production and composition of colostrum and transient milk. Animal 8:1021-1030. doi:10.1017/ S1751731114000950

Tokach, M. D., J. E. Pettigrew, B. A. Crooker, G. D. Dial, and A. F. Sower. 1992. Quantitative influence of lysine and energy intake on yield of milk components in the primiparous sow. J. Anim. Sci. 70:1864-1872.

Town, S. C., J. L. Patterson, C. Z. Pereira, G. Gourley, and G. R. Foxcroft. 2005. Embryonic and fetal development in a commercial dam-line genotype. Anim. Reprod. Sci. 85:301-316. doi:10.1016/j.anireprosci.2004.05.019

Yang, Y. X., S. Heo, Z. Jin, J. H. Yun, J. Y. Choi, S. Y. Yoon, M. S. Park, B. K. Yang, and B. J. Chae. 2009. Effects of lysine intake during late gestation and lactation on blood metabolites, hormones, milk composition and reproductive performance in primiparous and multiparous sows. Anim. Reprod. Sci. 112:199-214. doi:10.1016/j.anireprosci.2008.04.031

Zaleski, H. M., and R. R. Hacker. 1993. Variables related to the progress of parturition and probability of stillbirth in swine. Can. Vet. J. 34:109-113. 